\title{
Serials
Review
}

\section{Journal Finder: A Solution for Comprehensive and Unmediated Access to Journal Articles}

\author{
Terry W. Brandsma, Elizabeth R. Bernhardt, and Dana M. Sally
}

\begin{abstract}
The University of North Carolina at Greensboro's Jackson Library has introduced a new journal information service that makes finding and accessing journal articles easier and more effective than traditional methods. Journal Finder is part of a broader program to provide location-independent information access and through a single interface it allows users to connect directly to an electronic, full-text version of a journal; obtain local holdings and format information about a specific title; order a specific article from any journal through an unmediated document delivery service or interlibrary loan; and search other libraries' catalogs for journal holdings data. Developed in-house using a relational database structure, Journal Finder offers unique service advantages, while signaling a shift in the delivery of journal information from print subscriptions to access by means of separate articles in electronic or print formats. Serials Review 2002; 28:13-20. (C) 2002 Elsevier Science Inc. All Rights Reserved.
\end{abstract}

Academic librarians have long appreciated the importance of journal literature in the teaching, learning, and research activities of the faculty, staff, and students they serve as well as for their own professional development. Whether one formulates budgets, allocates resources for library materials, places orders for journal subscriptions, catalogs journal titles, or spends time at a public service desk identifying and locating journal articles for patrons, broad experience makes clear that a significant portion of academic library work and resources are devoted to the provision and support of this genre of information. One very obvious testament to the seminal role played by journal literature in meeting the information needs of the academy is the 680 million dollars spent annually on journals and the secondary sources used to identify relevant articles within them. ${ }^{1}$ Simply stated, journal articles provide critical information to support teaching, research, and scholarship of all kinds.

Today, the critical nature of journals places them at the very center of the budget and service programs of ac-

Brandsma is Information Technology Librarian, Walter Clinton Jackson Library, University of North Carolina, Greensboro, NC 27402-6175; e-mail: twbrands@uncg.edu.

Bernhardt is Electronic Journals/Information Delivery Librarian, Walter Clinton Jackson Library, University of North Carolina, Greensboro, NC 27402-6175; e-mail: brbernha@uncg.edu. Sally is Associate Director, Walter Clinton Jackson Library, University of North Carolina, Greensboro, NC 27402-6175; e-mail: Dana_Sally@uncg.edu. ademic libraries everywhere. Nearly from the inception of the modern periodical in the mid-seventeenth century, libraries have purchased, bound, and made relevant journal titles available to their patrons. ${ }^{2}$ Over time, as the number and subject coverage of journals increased, libraries added indexing and abstracting publications to collections to make identification of and access to journal material more effective and easier. With even further proliferation of periodical publications, libraries developed interlibrary loan programs to extend access beyond local collections. More recently, libraries have purchased electronic, full-text databases that make access to core journal material faster and more convenient. As the number and scholarly relevance of journals continue unabated, libraries are now adding mediated and unmediated document delivery services, electronic subscriptions, and pay-per-view options in attempts to expand their base of journal offerings while controlling costs. ${ }^{3}$ Again, all of this historic activity has provided the academic community with better access to the journal articles that drive its research and learning processes.

Along with many similar institutions around the country, The University of North Carolina at Greensboro's (UNCG's) Jackson Library has recognized the broad utility of effective and efficient access to journal literature. ${ }^{4}$ In 1998, the library's information technology department was among the first in the nation to develop an electronic journals database that enables library users to discover whether the library provides access to a journal in electronic, full-text form, and then connects them 
to that electronic journal. ${ }^{5}$ As the number of electronic journals that the library makes available has grown (through individual subscriptions, aggregator databases, publisher programs, and so forth), this database of electronic journal offerings and connections has become an increasingly vital part of its information service. ${ }^{6}$

Building on the technological base and service success of its electronic journals database, in August 2001 Jackson Library launched a unique, innovative information service that takes access and delivery of journal information to a new level of user-friendliness. The new program is called Journal Finder. Its basic aim is to allow library users to obtain, without mediation, any print or electronic journal article needed, whether or not the article is owned by the library. At the same time that Journal Finder appeared as a major service option on the library's Website, the electronic journals librarian sent letters to all UNCG faculty announcing the existence of this new service and describing its functionality. This same basic descriptive information was also published in the local student newspaper as well as in a publication that is distributed more broadly to the UNCG campus community. Simultaneously, reference librarians incorporated descriptions of Journal Finder's features and utility into all bibliographic instruction sessions offered at the beginning of the new academic year.

In what follows, the authors describe the features and capabilities of this new service, identify and describe the technical components that comprise its underlying structure, indicate how this service fits into a more comprehensive and integrated information program envisioned by the library, and comment briefly on expected immediate and longer-term implications of this service.

\section{Features and Capabilities}

Journal Finder is a locally developed software product that lets patrons search for a journal title and receive several access options for that title. The access options include online electronic holdings, the library's print holdings, document delivery options such as interlibrary loan or a document delivery service, and a link to other local library catalogs. To use Journal Finder, the patron goes to the Journal Finder Website (either directly at http:// library.uncg.edu/journalfinder/ or through the library's homepage at http://library.uncg.edu/) and searches for a known journal title (see Figure 1). When the search is executed, the user is provided with a Search Results screen containing a series of icons next to each of the titles that matched the search criteria (see Figure 2).

On the "Search Results" screen, the computer icon ("Online Access") represents the library's full-text online journals available through aggregators, direct subscriptions, complimentary access with a print subscription, or free Website access. By clicking on this icon, the user can view the available online access options for the journal title (e.g., InfoTrac, EbscoHost, JSTOR, and so forth) and the dates of coverage for each resource (see Figure 3). The user can then click on one of the online options, which will lead directly to the electronic journal or to an aggregator's database search screen.

The book icon ("In the Library") represents the library's print holdings in the online catalog. The icon will only display if the library holds that particular title. Clicking on this icon will execute a search within the library's online public access catalog (OPAC), retrieving full cata$\log$ information for the title.

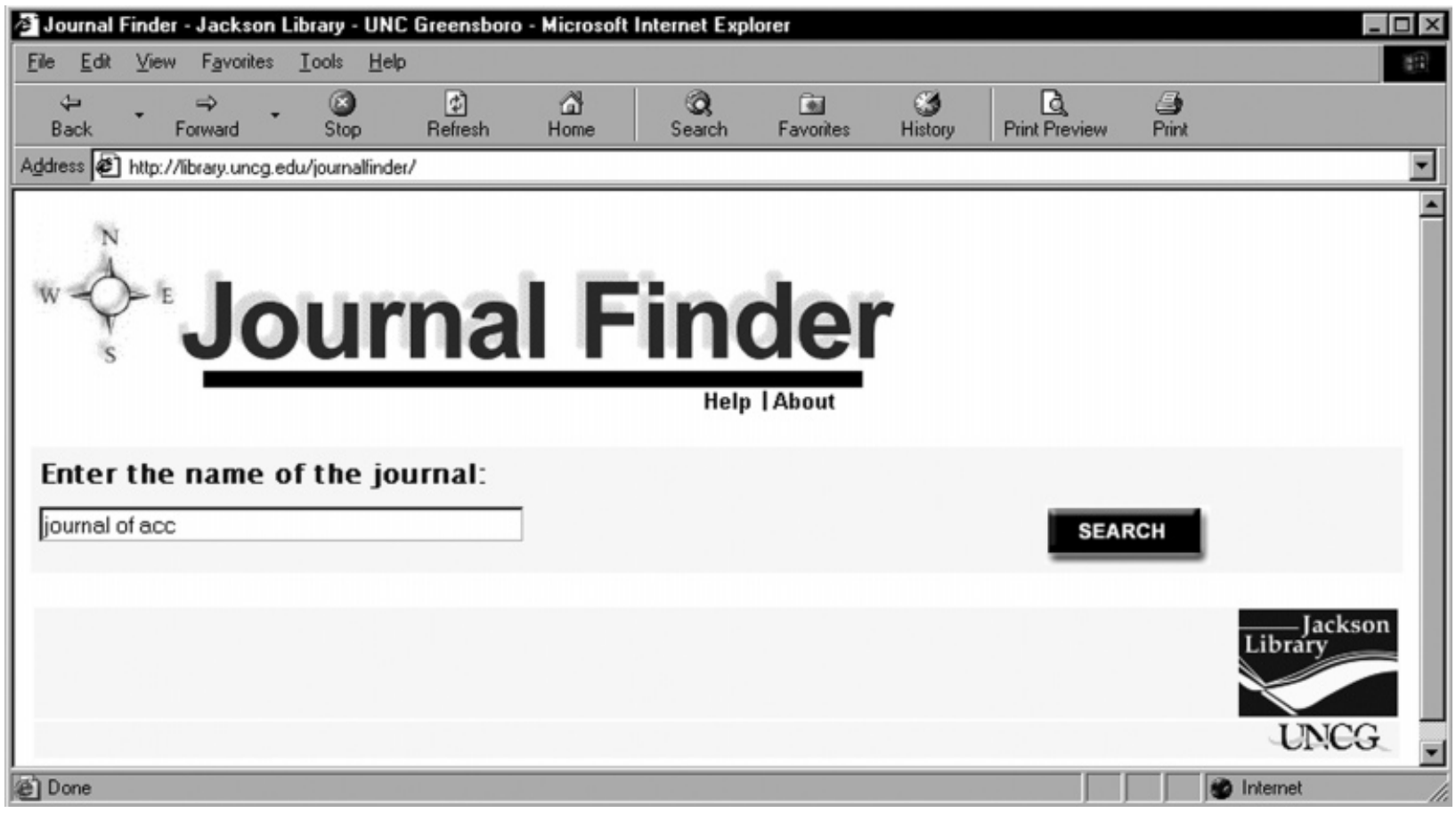

Figure 1. Journal Finder Website initial screen 


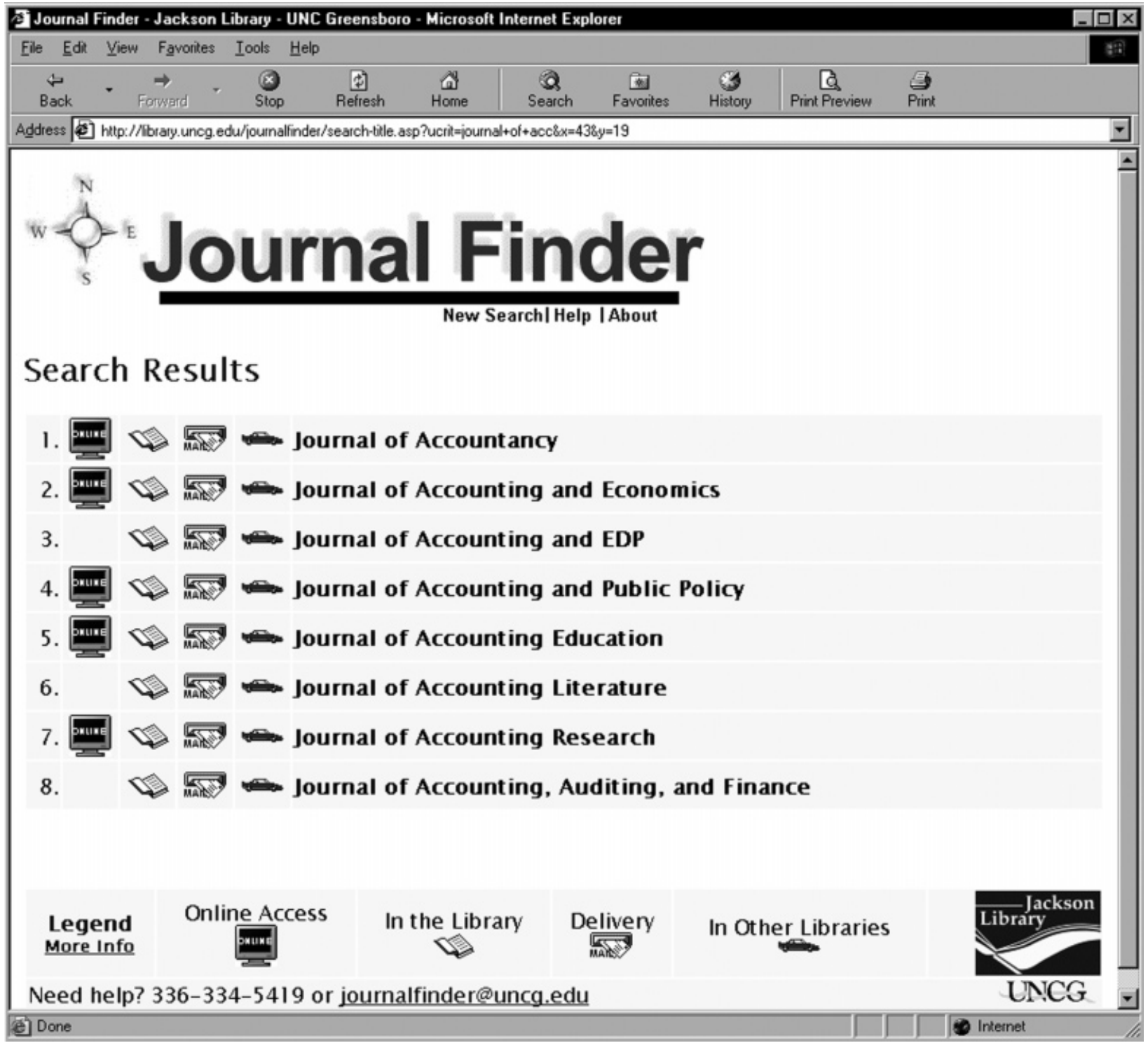

Figure 2. Search Results screen

The envelope icon ("Delivery") represents the document delivery options available through the library. This icon is displayed for all titles in the database. By clicking on this icon, the patron can choose to order the journal article either through conventional interlibrary loan or through an unmediated document delivery service (see Figure 4). This Web page provides the following information for each service: patron eligibility, estimated delivery times, and mail or e-mail delivery features. Ideally, the library's users gain access to journal articles through the library's subscriptions. If that is not possible, however, these delivery options exist. Jackson Library currently underwrites the cost of both document delivery and interlibrary loan for its users. An initial allotment of $\$ 75,000$ went toward the new document delivery service and the library continues to fund Interlibrary Loan at approximately $\$ 20,000$ per year. The library is tracking all usage statistics and will study the results to allocate future amounts.
The car icon ("In Other Libraries") allows the patron to search other library catalogs to find the desired journal. This icon is also displayed for all titles in the database. When users click on this icon, they are presented with a list of libraries in the local area that have that title (see Figure 5). The link will then lead directly to the journal's item record within the chosen OPAC. In addition, users are provided with Web links to many local and national OPACs so that they can search for the journal on their own. This option is especially important for UNCG's distance education students, enabling them to look for holdings in libraries closer to their homes or businesses.

When a patron searches for a journal title that is not found in Journal Finder, the database provides options for document delivery and interlibrary loan. By means of document delivery or interlibrary loan, the library anticipates that the user will be successful in obtaining any journal article. 


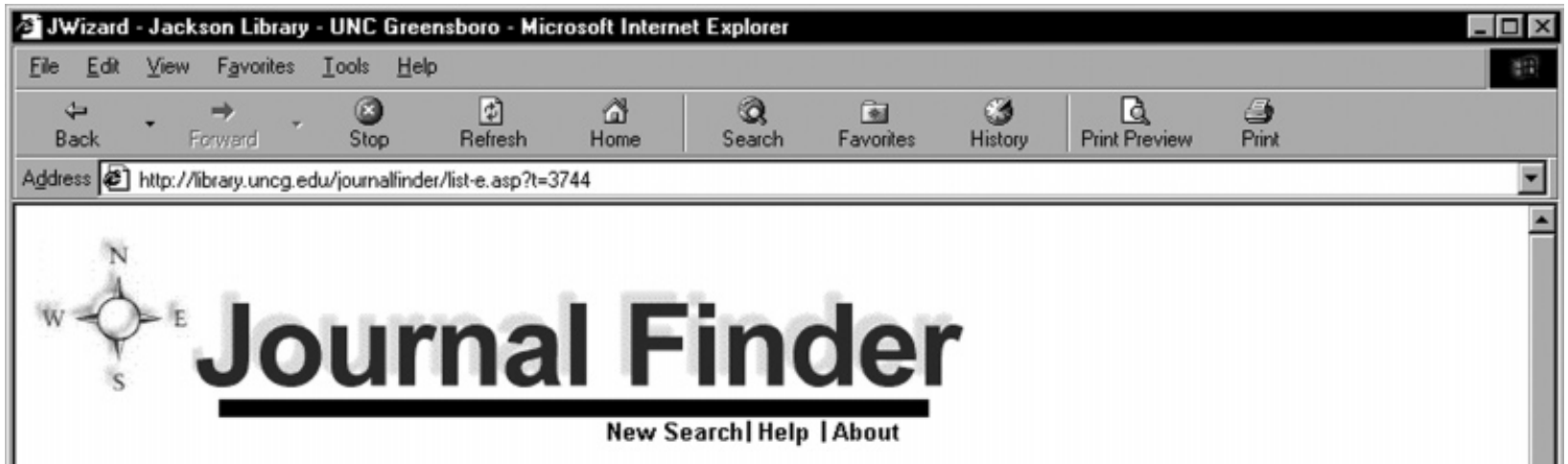

Online Access

Journal Title

lournal of Accountancy EbscoHost Academic Search Elite

lournal of Accountancy EbscoHost Business Source Elite

lournal of Accountancy EbscoHost Master File Premier

lournal of Accountancy Proquest Direct ABI/Inform Global

lournal of Accountancy Proquest Direct PA Research II Periodicals

lournal of Accountancy Lexis-Nexis Academic Universe

lournal of Accountancy Infotrac Onefile
Full-Text Begins Full-Text Ends

$7 / 1 / 93$

$7 / 1 / 93$

$7 / 1 / 93$

$1 / 1 / 91$

$1 / 1 / 91$

$1 / 1 / 87$

$11 / 1 / 89$

Need help? 336-334-5419 or journalfinder@uncg.edu

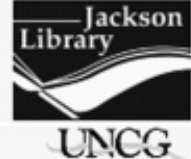

画

Figure 3. Electronic Access Options screen

Initially a team of eight librarians and staff entered all of the available data into Journal Finder. When new resources are purchased (e.g., Science Direct), the entire team works together to make sure all of the data is entered in a timely manner. The day-to-day administration of the Journal Finder database content is the responsibility of two professional staff, the electronic journals librarian and the serials cataloger. The electronic journals librarian maintains and enters online content into the Journal Finder database. The electronic journal titles are added to the database when they become available either through aggregators, subscriptions, complimentary access with print subscriptions, or free Website access. The aggregators' title lists are checked periodically to determine what titles need to be added or deleted from Journal Finder. The electronic journal links are checked weekly by an automated URL checker to indicate broken or moved links. If there are any broken or moved links, the electronic journals librarian makes the corrections to the database. As new titles are acquired for the Library's print collection, the serials cataloger adds the titles to the Journal Finder database as well as to the library's online system. The serials cataloger and the electronic journals librarian collaborate to provide the most up-to-date and accurate holdings in both the online system and the Journal Finder database.

\section{Behind-the-Scenes Components}

\section{Hardware and Software}

Journal Finder uses a relational database structure to store and retrieve journal access information. The system currently runs Windows NT Server, Microsoft SQL Server, and Internet Information Server. ${ }^{7}$ All of the Web interface pages, including those used by the Journal Finder administration team, are written as Active Server Pages ${ }^{8}$ (ASP) to allow for seamless interaction with the database. The current hardware is a Dell ${ }^{9}$ PowerEdge 2300 Server with 256 $\mathrm{MB}$ of RAM and an $8 \mathrm{~GB}$ hard disk, which is partitioned into a 2 GB system drive and a 6 GB application/data drive. Plans in the near future include upgrading the server as Web-based services continue to grow. The Journal Finder database itself uses about $35 \mathrm{MB}$ of space, but that will fluctuate as records are added, modified, and deleted.

\section{Relational Database Table Structure ${ }^{10}$}

Journal Finder content requires maintenance of several database tables (see Figure 6). The Titles table (tblTitles) is of primary importance. It contains each unique journal title, its associated identification (ID) number, and information on when it was entered and cataloged. The ID number is used to associate each unique title to at least one of several 


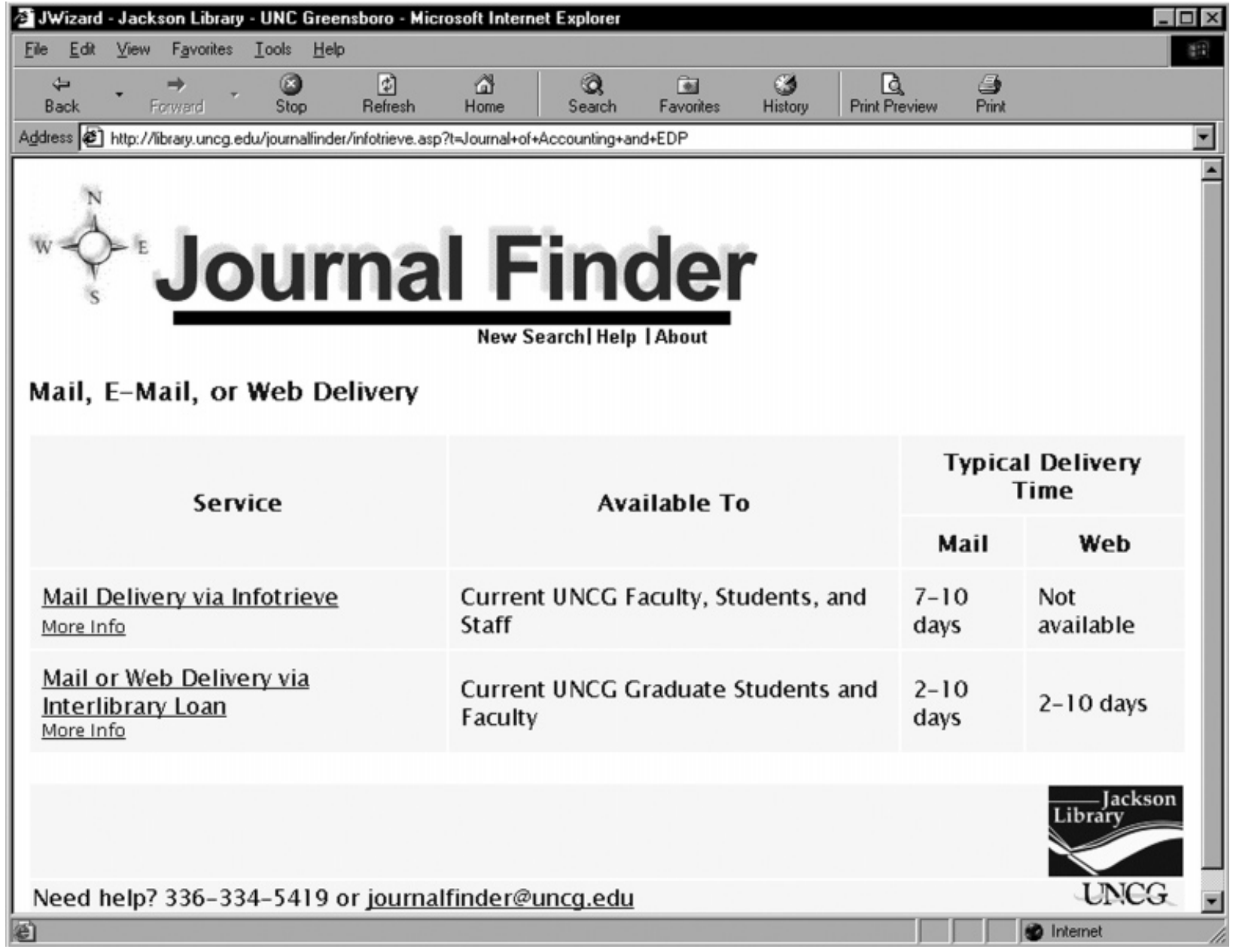

Figure 4. Document Delivery and Interlibrary Loan Options screen

access points identified in three other database tables. The AccessE table (tblAccessE) provides access points to electronic resources, whether they are stand-alone Websites or located within a specific vendor's electronic database. This table includes such items as a title ID (which is linked to the ID in the Titles table), the electronic source ID, full-text/ image coverage dates, the ISSN, dates indicating when the data was entered and updated, and the URL to the appropriate Web resource. The AccessJac table (tblAccessJac) contains links to holdings in the library's integrated online library system, DRA Classic. ${ }^{11}$ Data elements include the title ID (linked to the ID in the Titles table), the DRA database control number (DBCN), the ISSN, when the data was entered and updated, and any item-specific notes. The AccessLib table (tblAccessLib) contains the access points to other local libraries. When fully implemented, it will identify which local library holds each title, the ISSN, when the data was entered and updated, and the URL to search for the title within the remote library catalog, if available.

\section{Database Queries}

The database structure is invisible to the user. Query scripts written in ASP retrieve information from the data- base as requested by the user's input and then display the results via a Web page. Because the primary purpose of Journal Finder is to access a specific and known journal title, the search is for a title only (see Figure 1). Currently, the search screen provides only one option-search for all titles that begin with the entered term(s). The search is automatically right-truncated and is considered a phrase search if more than one term is entered. Although this meets the needs of most users, improvements are planned in the near future, such as retrieving nearby hits if no matches are found and possibly implementing a subject-search feature that will lead users to journals in a particular subject area.

The basic title search uses an SQL query to find matching titles in the Titles table, where the search term is matched against values in the "title" and "titleadded" fields. If matches are found, secondary queries are run to determine the journal's availability at each access point. The unique ID is first compared to records in the AccessE table to discover if electronic access to the journal title exists. If so, the ASP script displays the computer icon (see Figure 2), which links to another ASP script that searches for matching electronic resources. Selecting the icon leads the user to a list of electronic resources that contain the 


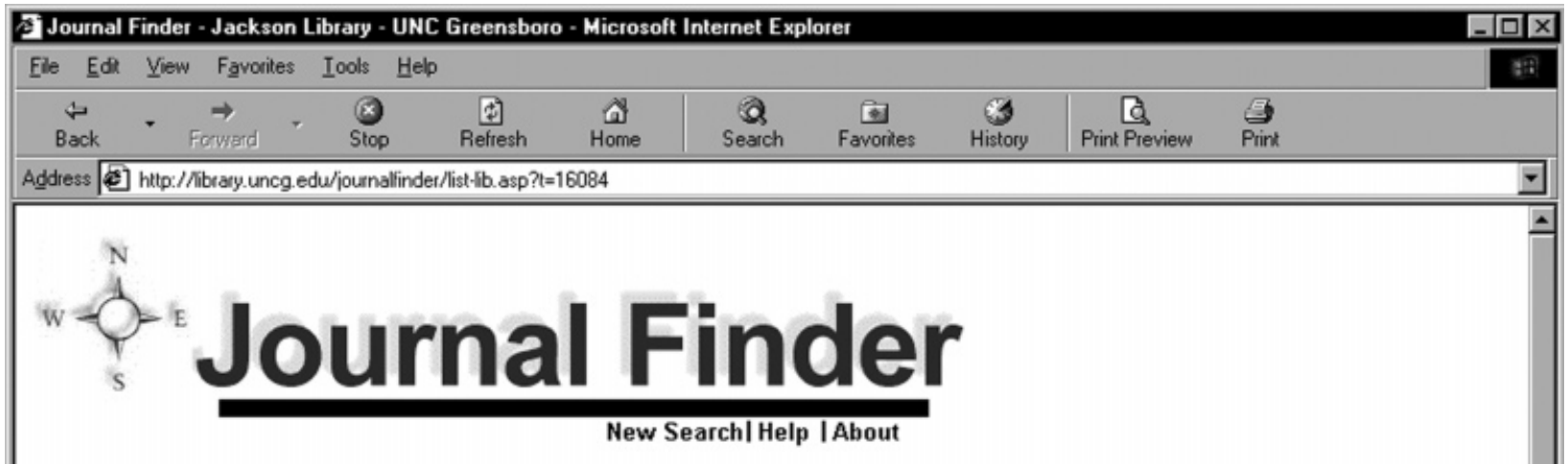

In Other Libraries

These libraries in Greensboro have some printed issues of Journal of Accounting Literature. Follow the link for more information.

- PICA (Benett, Greensboro, Guilford, and Salem Colleges and Elon University)

- North Carolina A\&T State University

You can use these resources to find out what libraries outside Greensboro have some printed issues of Journal of Accounting Literature.

- Academic Libraries in North Carolina and South-Central Virginia

- Libraries Around the World

Need help? 336-334-5419 or journalfinder@uncg.edu

Figure 5. Search Other Libraries Options screen

full-text journal, along with dates of coverage (see Figure $3)$. Selecting any of the journal title links at this point will send the user directly to the appropriate vendor's database or Website, or to the journal level within the vendor's database, if this function is provided. If journal-level access is not available, intermediate help screens inform the user of how to find a specific title within each database. The URL to each resource is uniquely configured within the Journal Finder database. Several hidden scripts are used to detect whether the user is on-campus or offcampus. On-campus users are sent directly to the resource, whereas off-campus users are required to authenticate prior to accessing subscription databases.

The title ID is then compared to records in the Access$\mathrm{Jac}$ table to determine if a record for that journal is in the online catalog. If so, the ASP script places the book icon on the results page (see Figure 2) and generates a URL that leads the user directly to the appropriate online catalog record. By clicking on the icon, the user can see which volumes of the journal the library has and all associated call numbers and locations. This search uses the unique DRA database control number to locate the record within the Web-based OPAC.
The two remaining access points, "document delivery" and "search other libraries," are always displayed on the title Search Results screen (see Figure 2). When users select the envelope icon, they are given the option to order the journal article through a document delivery service or through the library's Interlibrary Loan unit. Both of these options require local authentication prior to granting access to the necessary forms. Authentication requires that users enter their University Identification Number, which is then matched against the list of current students, faculty, and staff. The document delivery service also requires that first-time users register to obtain a username and password granting them access to the service. Accounting information is also provided, so that the library is billed for any orders.

The car icon provides links to many area library online catalogs. By loading the journal holdings information from several local libraries into the Journal Finder database, Jackson Library hopes to provide a simplified regional union catalog for serials for all participating institutions. When a search identifies the journal title as being held at a local library, the name of the library will be displayed as a link into their OPAC. If possible, this 




Figure 6. Database table structure

link will lead directly to the journal's item record. If local holdings are not identified, links to many regional and national OPACs are made available. In this way, users can search for the journal in the geographic location and/ or catalog of their choice.

\section{Program Context and Implications}

As conceived and implemented, Journal Finder is a natural extension of Jackson Library's basic aim to provide its users direct, unfettered access to information, especially full-text journal information. For years the library at UNCG, like most other academic libraries, has sought to expand its electronic journal holdings so that users can access journal information on computers located in the library, in their offices, at home, or from wherever they are able to connect to the Internet. At its core, Journal Finder attempts to provide a user interface for journal information that comprehends all journals. Journal Finder extends and significantly enhances the library's goal to provide direct, location-independent access to needed materials.

One of the more exciting features that Journal Finder offers is unmediated document delivery - the ability to order any article from any journal, whether or not this article is located in a print journal owned by the library, and have it delivered to one's home or office. For those UNCG students and staff working, learning, and studying at distant locations, this is a necessary service, since coming to the campus library is often not practical. Such a programmatic approach to providing journal literature is very beneficial to the general-user community and critically important to the library's success in supporting users enrolled in distance education courses and programs.

But what about local users? Will they find this feature of Journal Finder attractive and choose to order articles for office delivery rather than coming to the library on campus to consult the print journal? Similarly, will users prefer ordering through unmediated document delivery as opposed to obtaining the article through interlibrary loan? The short answer to these questions is that no one knows at this point which method of access, if any, will become predominant. From the standpoint of overall program strategy, the library hopes to build a core collection of electronic journals that meets the immediate needs of most disciplines and users on campus. If this fundamental objective is met, then the need for users to go beyond these core electronic offerings should be at- 
tenuated. From the program's outset, internal access statistics and information from the document delivery vendor will be used as essential data in continuing to assess and build core journal resources. Despite the best efforts to build and refine these core resources, the library recognizes that the need to go beyond them will persist.

Even less clear at present is the impact that Journal Finder will have on conventional interlibrary loan activity, which has steadily increased at UNCG over the past several years. Since Journal Finder provides a convenient alternative to interlibrary loan, one might reasonably surmise that activity in this traditional service area will decline. The nature and extent of putative declines, however, cannot be determined in advance; discovering whether any real reduction in interlibrary loan volume is related to Journal Finder will need to await empirical data on its use.

Jackson Library at UNCG is very excited about providing Journal Finder to its faculty, staff, and students. It is a service that promises great utility to the user, but it is also one that portends inevitable resource shifts within the library, perhaps presaging a shift within the arena of journal access from a subscription to a "separate" or "article" basis. ${ }^{12}$ This shift is not one that all libraries may be willing or have the resources to embrace. As vendors and publishers change the mode of article production from print to digital form, there has been a corresponding shift in the way articles are packaged and accessed. Collective availability of articles in conventional print subscriptions is yielding to separate availability of articles as individual digital files. This change could easily challenge the utility, efficacy, and primacy of the print journal as an information delivery mechanism in a manner similar to the scholarly journal's earlier supplanting of personal correspondence as a medium of information conveyance and exchange. Increasingly, libraries may find that providing information at the margins, or even at the core, of their needs is most effectively accomplished by providing journal articles as print or digital separates. Journal Finder is UNCG's foray into this new and as yet uncharted service arena. Its intent is to provide comprehensive information about the availability of specific journals, regardless of their format, and to bridge the divide between conventional subscriptionbased and separate digital-based article access. As a new, untested service with consequences that are neither to- tally predictable nor wholly controllable, Journal Finder is clearly not without risk and therefore may not suit every library's approach to information provision. At UNCG, the anticipated support and service advantages were judged to be worth the reasonable risks involved.

\section{Notes}

1. "Library Acquisition Expenditures, 1999-2000: US Public, Academic, Special and Government Libraries," in The Bowker Annual: Library and Book Trade Almanac, 46th ed. (New Providence, NJ: RR Bowker, 2001), 397-405, table 2. This source further shows that academic libraries in the US spend an approximate average of 48 percent of their materials budgets for periodical/serial publications.

2. Elizabeth L. Eisenstein, The Printing Press as an Agent of Change: Communications and Cultural Transformations in Early Modern Europe (Cambridge, UK: Cambridge University Press, 1979), 460-62.

3. Michaelyn Haslam and Eva Stowers, "Library-Subsidized Unmediated Document Delivery," Library Resources and Technical Services 45, no. 2 (April 2001): 80-89.

4. Jackson Library's 81.5 full-time equivalent (FTE) staff supports a population of approximately 11,250 FTE students and 700 FTE faculty at The University of North Carolina at Greensboro.

5. John W. Felts, Jr., "Now You Can Get There From Here: Creating an Interactive Web Application for Accessing Full-text Journal Articles From Any Location," Library Collections, Acquisitions, \& Technical Services 25 (2001): 281-90.

6. Currently UNCG's electronic journals database contains over 9,000 unique journal titles. Holdings for titles vary.

7. Microsoft and its product names are registered trademarks of $\mathrm{Mi}-$ crosoft Corporation. Additional information about these products can be found at http://www.microsoft.com/.

8. Additional information on Active Server Pages (ASP) can be found at http://msdn.microsoft.com/asp/, as well as many other Websites such as http://www.asp101.com/, http://www.learnasp.com/, and http://www.aspfaqs.com/.

9. Additional information about Dell Computer Corporation and its products can be found at http://www.dell.com/.

10. In order to describe the components of Journal Finder and how they work, a simplified database structure is presented for ease of understanding. Please contact the authors for additional details about system components.

11. Additional information about DRA (Data Research Associates, Inc.) and its products and services can be found at http://www. dra.com/.

12. For more on this topic, see "Document Delivery versus Subscriptions," Scholarly Communications Report 5, no. 5 (May 2001): 4. 